\title{
Sodium Valproate versus Amitriptyline in the Prophylactic Treatment of Migraine
}

\author{
Shahjada Mohammad Dastegir Khan 1 , Salma Akhtar Walida², Abul Kalam Mohammed Shoab \\ Muhammad Abdul Momen Khan ${ }^{4}$, Sakhawat Hossain ${ }^{5}$, Md. Shaheen Wadud', \\ Khan Md. Muzammel Hossain ${ }^{7}$

\begin{abstract}
${ }^{1}$ Assistant Professor, Department of Neurology, Sir Salimullah Medical College, Dhaka, Bangladesh; ${ }^{2}$ Assistant Professor, (Obs \& Gynae), Department of Gynae Oncology, National Institute of Cancer Research and Hospital, Dhaka, Bangladesh; ${ }^{3}$ Assistant Professor, Department of Neurology, Sylhet MAG Osmani Medical College, Sylhet, Bangladesh; ${ }^{4}$ Assistant Professor, Department of Neurology, National Institute of Neurosciences \& Hospital, Dhaka, Bangladesh; ${ }^{5}$ Professor and Head, Department of Neurology, Sir Salimullah Medical College, Dhaka, Bangladesh; ${ }^{6}$ Associate Professor(CC), Department of Neurology, Dhaka National Medical College, Dhaka, Bangladesh; ${ }^{7}$ Associate Professor, Department of Pharmacology, MAG Osmani Medical College, Sylhet, Bangladesh
\end{abstract}

[Received on: 22 April 2021; Accepted on: 12 May 2021; Published: 1 July 2021]

\begin{abstract}
Background: Drug prophylaxis of migraine is a safe and effective way of reducing the attack of headache frequency and the economic burden of migraine. Several drugs have been shown to be efficacious in double-blind placebo-controlled trials. Many patients avoid the regular intake of prophylactic drugs because of fear about the side effects, tolerance and addiction. Another reason for the low acceptance of migraine prophylaxis is that the efficacy of most drugs is limited and the burden of treatment cost. In this study two effective drugs, Amitriptyline and Sodium valproate are evaluated regarding their safety and efficacy. This study shows the comparative effectiveness, safety of both drugs and withdraw all the misconception about the prophylactic treatment of migraine among the patients and improve their life style adjustment and reduce the economic burden of the society. Objective: The purpose of the present study was to observe and compare the efficacy of Sodium Valproate and Amitriptyline in the prophylactic management of migraine patients. Methodology: This experimental study was carried out in the Department of Neurology at Sir Salimullah Medical College \& Mitford Hospital, Dhaka, Bangladesh during the period from January 2013 to December 2013. A total of 120 patients with migraine were selected of which 60 were treated with Amitriptyline (Group-A) and another 60 were treated with Sodium Volproate (Group-B). Both groups were observed for 6 months and the improvement of headache regarding frequency, severity and duration of episodes of headache was recorded in every 2 months follow up. Adverse effect of the drugs also monitored in both group. Result: Out of 120 patients the mean age was $32 \pm 8.64$ years and $34.23 \pm 8.09$ in group-A and group-B respectively $(\mathrm{p}=0.147)$. There were $23(38.3 \%)$ male and $37(61.7 \%)$ female in group-A; whereas $17(28.3 \%)$ male and 43 $(71.7 \%)$ female in group- $\mathrm{B}(\mathrm{p}=0.245)$. Thus the study was an age and sex matched study. It was observed that one third 20(33.3\%) patients were house wife's in group-A and 24(40.0\%) in group-B. The difference was not statistically significant $(\mathrm{p}>0.05)$ between two groups. Frequency of attack per month before treatment was $6.25 \pm 5.21$ in group-A and $7.80 \pm 4.1$ in group-B. Frequency of attack per month after 2 months treatment was $4.30 \pm 4.14$ and $6.19 \pm 4.10$ in group-A and group-B respectively. Frequency of attack per month after 4 months treatment was $3.78 \pm 2.53$ in group-A and $4.89 \pm 2.83$ in group-B. Frequency of attack per month after 6 months treatment was $1.70 \pm 1.42$ in group-A and $3.1 \pm 1.98$ in group-B. Frequency of attack per month after 2, 4 and 6 months treatment was statistically significant $(\mathrm{p}<0.05)$ between two groups. It was observed that majority $(88.3 \%)$ patients were improved headache in group-A and $23(38.3 \%)$ in group-B. The difference was statistically significant $(\mathrm{p}<0.05)$ between two groups. Conclusion: The pain intensity score is significantly decline in patients who received amitriptyline after treatment and almost similar in patients who received sodium valproate. Improved headache most of the patients who received Amitriptyline and less adverse effects developed in this group. Amitriptyline is more effective, seems to be safer than Sodium Valproate. [Journal of National Institute of Neurosciences Bangladesh, July 2021;7(2):126-131]
\end{abstract}

Keywords: Headache; migraine; sodium valproate; amitriptyline 
Correspondence: Dr. Shahjada Mohammad Dastegir Khan, Assistant Professor, Department of Neurology, Sir Salimullah Medical College, Dhaka, Bangladesh; Email: dastegir69@gmail.com; Cell no.:+8801711466644

Conflict of interest: There is no conflict of interest relevant to this paper to disclose.

Funding agency: This research project was not funded by any group or any institute.

Contribution to authors: MSDK, SAW, AKMS and MAMK involved in protocol preparation, data collection and literature search up to manuscript writing. SH involved in preparation and revision of this manuscript.

How to cite this article: Khan MSD, Walida SA, Shoab AKM, Khan MAM, Hossain S. Sodium, Hossain KMM, Wadud MS, Valproate versus Amitriptyline in the prophylactic Treatment of migraine. J Natl Inst Neurosci Bangladesh, 2021; 7(2): 126-131

Copyright: (C2021 Khan et al. Published by Journal of national institute of Neurosciences Bangladesh. This article is published under the creative commons CC-BY- NC License (https://creativecommons.org/licenses/by-nc/4.0/). This license permits use, distribution and reproduction in any medium, provided the original work is properly cited, and is not used for commercial purposes.

\section{Introduction}

Migraine is one type of primary headache presents with episodic headache that is usually unilateral, pulsating in quality, moderate to severe in intensity and exacerbated by physical activity, associated with nausea or vomiting, photophobia and phonophobia. The disorder is classified as migraine with aura and migraine without aura, according to the presence or absence; respectively of premonitory neurological symptoms ${ }^{1}$. It is the second most common cause of headache and about $16 \%$ of all primary headache ${ }^{2}$. It is annually affecting $18.0 \%$ of women, $6.0 \%$ of men and $4.0 \%$ of children and common in people who are in lower socioeconomic groups ${ }^{3}$. Migraine is now ranked by the World HeSalth Organization as number 19 among all diseases causing worldwide disability. A pharmaco-economic study of migraine in the USA calculated that the annual loss of productivity due to migraine cost more than USD 13 billion per year ${ }^{4}$ and some studies have suggested that the cost might be as much as $\$ 17$ billion per year 5 .

The management of Migraine involves non pharmacological strategies, abortive and prophylactic drugs. Prophylactic treatment is necessary when the migraine attack is unacceptably frequent, prolonged, severe, and unresponsive to acute medication, associated with hemiparesis or aura ${ }^{6}$. So management is designed to reduce the frequency, duration and /or severity of the attack. In addition, prophylactic treatment makes migraine attack more responsive to acute migraine therapies, reduces migraine associated disability, improves the patient's ability to maintain normal life style and decreases healthcare cost? ${ }^{7}$.

A variety of drugs are used in the prophylaxis of migraine. The basic principle in management of migraine is avoiding the trigger factors and blocking the mediator like serotonin, substance $\mathrm{p}$, histamine and prostaglandin ${ }^{8}$. Amitriptyline is the most frequently used drug in migraine prophylaxis, it was first used in the treatment of migraine in 1964, and in study on 27 patients, and resulted in significant improvement in 56.0\% patients ${ }^{9}$.
Anticonvulsant drugs have been used for migraine prophylaxis since 1970 with carbamazepine as the first drug of this group 7 . Publication of four RCTs on sodium valproate for migraine prophylaxis has shown that there is reduction in the number of migraine attacks or days with migraine by about $50.0 \%$ cases $^{10}$. In this context, Sodium valproate can be used in the prophylaxis of migraine.

The mechanism of action of sodium volproate in migraine prevention might be related to the facilitation of GABA-mediated neurotransmission. Valproate enhances GABA activity within the brain by inhibiting its degradation, stimulating its synthesis and release and directly enhancing postsynaptic effects. Active metabolites (e.g. 2-en-valprotic acid) accumulates in the brain have an anticonvulsant effect ${ }^{11}$. Most important adverse effects are nausea, alopecia, vomiting, tremor, weight gain, hair loss, drowsiness, ataxia, hepatotoxicity, pancreatitis are most serious adverse effects. It carries a high risk of congenital abnormality. Both amitriptyline and sodium valproate have class 1 recommendation for migraine prophylaxis. There are few studies, comparing the relative efficacy and tolerability of Sodium valproate and amitriptyline ${ }^{12}$. In Bangladesh perspective no similar study was done previously. So this study was revealed the efficacy of sodium valproate and amitriptyline in migraine prophylaxis.

\section{Methodology}

This experimental study was conducted in Department of Neurology at Sir Salimullah Medical College \& Mitford Hospital, Dhaka, Bangladesh from January 2013 to December 2013 for a period of one year. All attended patients of both sexes between 12-45 years who presented with migraine in the Out Patient Department of Neurology, Sir Salimullah Medical College and Mitford Hospital, fulfilling the inclusion criteria were considered as study population. Informed written consent was taken from each patient or his/her attendant. All information regarding history and 
physical findings and other risk factors and relevant physical examination like nervous system examination, selected general and systemic examination recorded. Everyday all patients attending in the outdoor were divided into even number and odd number. Even number given Amitriptyline and odd number given Sodium Valporate with doses, Sodium Valporate: 400-1200 mg/d \& Amitriptyline: $10-50 \mathrm{mg} / \mathrm{d}$. for 6 months. All patients collected till the required number of sample size of 120 was reached. Then total patients divided into group A and group B. Even number patients considered as group A and odd number considered as group B. Then both groups were observed for 6 months and the improvement of headache regarding frequency, severity and duration of episodes of headache was recorded in every 2 months follow up. Adverse effect of the drugs also monitored in both group, In terms of nausea, dyspepsia, sedation, drowsiness, dry mouth, dizziness, increased appetite, weight gain, and ataxia. The data gathered was expressed by descriptive statistical methods (average, frequency distribution, percentage, mean \& standard deviation) as applicable. Statistical analyses related with this study were performed by use of SPSS 17.0 package program. Comparison between groups was done by standard statistical test e.g. Chi-square test. A probability value (p) of $<0.05$ was considered as significant.

\section{Results}

One hundred and twenty (120) migraine patients were selected from which 60 patients of group-A (Amitriptyline treated group) and 60 patients of group-B (Sodium Valprote treated group) were analyzed. The mean age was found $32 \pm 8.64$ years in group A and $34.23 \pm 8.09$ years in group B. The mean age difference was not statistically significant $(p>0.05)$ between two groups. Two third 37(61.7\%) patients were female in group-A and 43(71.7\%) in group-B. The difference was not statistically significant $(p>0.05)$ between two groups. One third 20(33.3\%) patients were house wife's in group-A and 24(40.0\%) in group-B. The difference was not statistically significant $(p>0.05)$ between two groups (Table 1$)$.

Frequency of attack per month before treatment was $6.25 \pm 5.21$ in group-A and $7.80 \pm 4.1$ in group-B. Frequency of attack per month after 2 months treatment was $4.30 \pm 4.14$ and $6.19 \pm 4.10$ in group-A and group-B respectively. Frequency of attack per month after 4 months treatment was $3.78 \pm 2.53$ in group-A and
$4.89 \pm 2.83$ in group-B. Frequency of attack per month after 6 months treatment was $1.70 \pm 1.42$ in group-A and $3.1 \pm 1.98$ in group-B. Frequency of attack per month after 2, 4 and 6 months treatment was statistically significant $(\mathrm{p}<0.05)$ between two groups (Table 2$)$.

Table1: Distribution of the patients according to age, sex and duration

\begin{tabular}{lccl}
\hline Parameters & \multicolumn{2}{c}{ Group } & \multirow{2}{*}{ P Value } \\
\cline { 2 - 3 } & Group A & Group B & \\
\hline Age (Mean \pm SD) & $32 \pm 8.64$ & $34.23 \pm 8.09$ & $0.147 \mathrm{~ns}$ \\
Age Range & 13 to 45 & 19 to 45 & \\
(min-max) & & & \\
Gender & & & \\
- Male & $23(38.3 \%)$ & $17(28.3 \%)$ & $0.245 \mathrm{~ns}$ \\
- Female & $37(61.7 \%)$ & $43(71.7 \%)$ & \\
Occupation & & & \\
- Student & $14(23.3 \%)$ & $8(13.3 \%)$ & \\
- House wife & $20(33.3 \%)$ & $24(40.0 \%)$ & \\
- Service & $15(25.0 \%)$ & $17(28.3 \%)$ & $0.491 \mathrm{~ns}$ \\
- Farmer & $0(0.0 \%)$ & $2(3.3 \%)$ & \\
- Teachers & $3(5.0 \%)$ & $3(5.0 \%)$ & \\
- Others & $8(13.3 \%)$ & $6(10.0 \%)$ & \\
\hline
\end{tabular}

$\mathrm{ns}=$ not significant. $\mathrm{P}$ value reached from chi square test; Group-A $\quad(n=60)=$ Amitriptyline; Group-B $\quad(n=60)$; Sodium Valproate

Table 2: Distribution of the study patients by frequency of migraine $(n=120)$

\begin{tabular}{lcccc}
\hline Group & \multicolumn{4}{c}{ Frequency of attack per month } \\
\cline { 2 - 5 } & $\begin{array}{c}\text { Before } \\
\text { treatment }\end{array}$ & $\begin{array}{c}\text { After } \\
\text { 2 Months }\end{array}$ & $\begin{array}{c}\text { After } \\
\text { 4 Months }\end{array}$ & $\begin{array}{c}\text { After } \\
\text { 6 Months }\end{array}$ \\
\hline Group A & $6.25 \pm 5.21$ & $4.30 \pm 4.14$ & $3.78 \pm 2.53$ & $1.70 \pm 1.42$ \\
& $(2-25)$ & $(1-18)$ & $(1-12)$ & $(1-8)$ \\
Group B & $7.80 \pm 4.1$ & $6.19 \pm 4.10$ & $4.89 \pm 2.83$ & $3.1 \pm 1.98$ \\
& $(3-24)$ & $(2-20)$ & $(1-15)$ & $(1-13)$ \\
P value & $0.072 \mathrm{~ns}$ & $0.013 \mathrm{~s}$ & $0.025 \mathrm{~s}$ & $0.001 \mathrm{~s}$ \\
\hline
\end{tabular}

$\mathrm{s}=$ significant; $\mathrm{ns}=$ not significant, $\mathrm{P}$ value reached from unpaired t-test

It was observed that majority $(88.3 \%)$ patients were improved headache in group-A and $23(38.3 \%)$ in group-B. The difference was statistically significant $(p<0.05)$ between two groups. Follow up in terms of frequency, intensity and duration had been shown in the table (Table 3).

In group $\mathrm{A}$, nausea $5.0 \%$, dyspepsia $6.7 \%$, sedation $13.3 \%$, drowsiness $11.7 \%$, dry mouth $13.3 \%$, dizziness $8.3 \%$, increase appetite $5.0 \%$, weight gain $6.7 \%$ and ataxia $3.3 \%$ cases. In group B, nausea $25.0 \%$, 
dyspepsia $16.7 \%$, sedation $6.7 \%$, drowsiness $8.3 \%$, dry mouth $5.0 \%$, dizziness $18.3 \%$, increase appetite $20.0 \%$, weight gain $16.7 \%$ and ataxia $13.3 \%$ cases. In conclusion adverse effects are mild in group-A than group-B users which gradually decreasing throughout the period of study (Table 4).

Table 3: Distribution of study patients according to follow up considering headache $(\mathrm{n}=120)$

\begin{tabular}{lccc}
\hline Headache & Group-A & Group-B & P value \\
\hline Improved & $53(88.3 \%)$ & $23(38.3 \%)$ & $0.001 \mathrm{~s}$ \\
Not improved & $7(11.7 \%)$ & $37(61.7 \%)$ & \\
\hline
\end{tabular}

$\mathrm{s}=$ significant, $\mathrm{P}$ value reached from chi square test

Table 4: Distribution of Study Patients According To Adverse Effect $(\mathrm{n}=120)$

\begin{tabular}{lcc}
\hline Averse Effect & Group A & Group-B \\
\hline Nausea & $3(5.0 \%)$ & $15(25.0 \%)$ \\
Dyspepsia & $4(6.7 \%)$ & $10(16.7 \%)$ \\
Sedation & $8(13.3 \%)$ & $4(6.7 \%)$ \\
Drowsiness & $7(11.7 \%)$ & $5(8.3 \%)$ \\
Dry mouth & $8(13.3 \%)$ & $3(5.0 \%)$ \\
Dizziness & $5(8.3 \%)$ & $11(18.3 \%)$ \\
Increase appetite & $3(5.0 \%)$ & $12(20.0 \%)$ \\
Weight gain & $4(6.7 \%)$ & $10(16.7 \%)$ \\
Ataxia & $2(3.3 \%)$ & $8(13.3 \%)$ \\
\hline
\end{tabular}

\section{Discussion}

This comparative prospective study was carried out with an aim to observe and compare the efficacy of Sodium valproate and Amitriptyline in the prophylactic management of migraine patients. A total of 120 were included in this study and among them 60 patients received Amitriptyline and rest 60 patients received Sodium valproate were considered as group A and group $\mathrm{B}$ respectively, in patients age belonged to 12 to 45 years presenting with migraine as per criteria fixed by the International Headache Society (IHS).

The mean age was $32 \pm 8.64$ years varied from 13 to 45 years in group A and $34.23 \pm 8.09$ years varied from 19 to 45 years in group B. The mean age was almost alike between two groups no statistical significant $(p>0.05)$ difference was found between two groups, and no relationship of headache in migraine with age found. Similarly, Kalita et $\mathrm{al}^{12}$ and Rao et $\mathrm{al}^{8}$ showed mean age of their migraine patients were 32 years varied from 16 to 49 years and 28.6 years varied from 16 to 53 years respectively. Almost similar age range observed by another study ${ }^{13}$ where they found age range varied from 12 to 50 years. In this study it was observed that migraine is more common in female subject, where almost two third $(61.7 \%)$ of the patients were female in group A (Amitriptyline) and $71.7 \%$ in group B (Sodium valproate). Male to female ratio were 1:1.2 and 1:2.5 in group A and group B respectively. The difference was not statistically significant $(p>0.05)$ between two groups, and females are predominant in both groups. Similarly, two studies ${ }^{12-13}$ have observed identical incidence of female predominant of their study patients having migraine and thus, support the present study, where they found almost male to female ratio was 1:4. In a cross sectional study 4 showed the crude prevalence of migraine was $18.2 \%$ and $6.5 \%$ in female and male respectively. As regards to the incidence of migraine, a number of investigators ${ }^{8-9}$ found in their studies that migraine was predominant in female subject.

Regarding the occupation it was observed that one third $(33.3 \%)$ patients were house wives in group-A (Amitriptyline) and $40.0 \%$ in group-B (Sodium valproate); statistically not significant $(\mathrm{p}>0.05)$. It was observed by study ${ }^{13}$ that housewife $51.4 \%$, student $21.6 \%$, service $18.9 \%$, business $2.7 \%$ and others $5.4 \%$, which are comparable with the current study.

The present study found that frequency of attack per month before treatment was $6.25 \pm 5.21$ in group-A and $7.80 \pm 4.1$ in group B. Frequency of attack per month after 2 months treatment was $4.30 \pm 4.14$ and $6.19 \pm 4.10$ in group A and group B respectively. Frequency of attack per month after 4 months treatment was $3.78 \pm 2.53$ in group-A and $4.89 \pm 2.83$ in group-B. Frequency of attack per month after 6 months treatment was $1.70 \pm 1.42$ in group-A and $3.1 \pm 1.98$ in group-B. Frequency of attack per month after 2nd, 4th and $6^{\text {th }}$ months of treatment were significantly $(p<0.05)$ decline in both groups but more decline in group-A.

Regarding the pain intensity scale it was observed that pretreatment period, all patients had severe pain intensity in both groups and their mean pain intensity score was $8.98 \pm 0.83$ varied from 8 to 10 in group A (Amitriptyline) and $8.67 \pm 0.9$ varied from 8 to 10 in group B (Sodium valproate). After treatment received during $6^{\text {th }}$ months of follow-up $86.7 \%$ patients had mild pain intensity in group $\mathrm{A}$, whereas in group-B, moderate intensity was found $43.3 \%$ and severe intensity found $50 \%$ of the patients. In addition the mean pain intensity score was $2.78 \pm 0.71$ varied from 2 to 5 in group A and $7.10 \pm 1.92$ varied from 3 to 10 in group B. The pain intensity score after 6 months of treatment was significantly $(p<0.05)$ decline from pretreatment period in group-A but almost similar between pretreatment period with after 6 months of treatment in group B, which is similar with a study ${ }^{13}$, where it found the mean 
pain intensity score was $6.95 \pm 0.62$ and after 3 months the mean pain intensity score was $5.65 \pm 0.59$ in sodium valporate group. Another study ${ }^{13}$ showed on migraine prophylaxis, both divalproate extended release (DVA-ER) and amitriptyline (AMT) resulted in significant improvement in the entire outcome parameters at 3 and 6 months compared with baseline. At 3 months, improved in pain intensity score $(80.7 \%$ vs 64\%) compared with AMT. The reported efficacy of DVA/ (sodium valproate (SVA) has ranged between $45 \%$ and $86.2 \% 11,{ }^{14-15}$. Most of these studies have compared the headache frequency as the primary end point except 2; one study compared duration, frequency, and severity of migrain $\mathrm{e}^{16}$ and the other study compared the severity, general pain VAS score, and frequency of headache ${ }^{17}$. In addition to headache frequency, Kalita et al. ${ }^{12}$ have also included severity, overall improvement in headache, functional disability, and number of rescue medications, which have lead to a more comprehensive evaluation.

In this study it was observed during follow up majority $(88.3 \%)$ of the patients improved headache in group-A (Amitriptyline) and only $38.3 \%$ in group-B (Sodium valproate), which was significantly $(\mathrm{p}<0.05)$ higher in group A. In the divalproate extended release (DVA-ER) group, $74.7 \%$ patients had improved with respect to the headache frequency, whereas in the amitriptyline (AMT) improvement at 3 months and $69.3 \%$ at 6 months in DVA-ER group. In the AMT group, these were $64.0 \%$ and $56.0 \%$, respectively. In a small double blind crossover study done by Couch $^{18}$ on 27 subjects treated with amitriptyline and placebo, $56.0 \%$ were more than $50.0 \%$ improved. In an uncontrolled study ${ }^{19}$ of 110 subjects reported that $72 \%$ were improved by $\geq 50 \%$ with amitriptyline.

In this present study it was observed that in group-A nausea $5.0 \%$, dyspepsia $6.7 \%$, sedation $13.3 \%$, drowsiness $11.7 \%$, dry mouth $13.3 \%$, dizziness $8.3 \%$, increase appetite $5.0 \%$, weight gain $6.7 \%$ and ataxia $3.3 \%$ cases. In group B nausea $25.0 \%$, dyspepsia $16.7 \%$, sedation $6.7 \%$, drowsiness $8.3 \%$, dry mouth $5.0 \%$, dizziness $18.3 \%$, increase appetite $20.0 \%$, weight gain $16.7 \%$ and ataxia $13.3 \%$ cases. In conclusion adverse effects are mild in group-A than group-B users which gradually decreasing throughout the period of study. Dodick et $\mathrm{al}^{7}$ obtained that treatment-emergent adverse events (TEAEs) were reported in $85.9 \%$ in the topiramate group and $88.8 \%$ in the amitriptyline group. Adverse effects of amitriptyline include drowsiness, weight gain, and anticholiner $\neg$ gic symptoms such as dry mouth $^{20}$ and also adverse effect of sodium valproate are nausea, vomiting, tremor, drowsiness, ataxia, weight gain, hepatotoxicity, and pancreatitis ${ }^{21}$.

\section{Conclusion}

This study was undertaken to observe and compare the efficacy of Amitriptyline and Sodium Valproate in the prophylactic management of migraine patient. Majority of patients having migraine in $4^{\text {th }}$ decade and female predominant. The pain intensity score was significantly decline in patients who received Amitriptyline after treatment and almost similar in patients who received sodium valproate. Improved headache most of the patients who received Amitriptyline and less adverse effects developed in this group. Amitriptyline is more effective, seems to be safer than Sodium Valproate.

\section{References}

1. Lipton RB, Bigal ME. The epidemiology of migraine. The American Journal of Medicine Supplements. 2005;118:3-10

2. Lipton RB, Bigal ME. Migraine: epidemiology, impact, and risk factors for progression. Headache: The Journal of Head and Face Pain. 2005;45:S3-13

3. Powers SW, Coffey CS, Chamberlin LA, Ecklund DJ, Klingner EA, Yankey JW, et al. Trial of amitriptyline, topiramate, and placebo for pediatric migraine. New England Journal of Medicine. 2017;376(2):115-24

4. Lipton RB.'Menstrually related migraine: Implications for employers and managed care'. 2005; 9: S800-S804

5. Mennini FS, Gitto L, Martelletti P. Improving care through health economics analyses: cost of illness and headache. J headache and pain. 2008; 9(4): 199-206

6. Leonardi M, Steiner TJ, Scher AT, Lipton RB. The Global Burden of migraine: measuring disability in headache disorders with WHO's Classification of Functioning, Disability and Health (ICF). J Headache Pain. 2005; 6(6): 429-40

7. Dodick DW, Freitag F, Banks J, Saper J, Xiang J, Rupnow M et al. Topiramate Versus Amitriptyline in Migraine Prevention: A 26-Week, Multicenter, Randomized, Double-Blind, DoubleDummy, Parallel-Group Noninferiority Trial in Adult Migraineurs. Clin Ther. 2009; 31: 542-559

8. Rao BS, Das DG, Taraknath VR, Sarma Y.'A double blind controlled study of propranolol and cyproheptadine in migraine prophylaxis', Open access journal indexed with Index Medicus. 2000; 48(3): 223-6

9. Yu S, Han X. Update of chronic tension-type headache. Current pain and headache reports. 2015;19(1):469

10. Sadeghian H, Motiei-Langroudi R. Comparison of Levetiracetam and sodium Valproate in migraine prophylaxis: A randomized placebo-controlled study. Annals of Indian Academy of Neurology. 2015;18(1):45

11. Freitag FG, Collins SD, Carlson HA.'A randomized trial of divalproex sodium extended-release tablets in migraine prophylaxis'. Neurology. 2002; 58: 1652-9

12. Kalita J, Bhoi SK, Misra UK. 'Amitriptyline vs divalproate in migraine prophylaxis: a randomized controlled trial'. Acta Neurol Scand. 2013; 128(1): 65-72

13. Chowdhury MI, Anwar Ullah AKM, Omar Hassan KM \& Majumder S."Sodium Valporate in Migraine Prevention Efficacy is the Same as Propranolol" JAFMC Bangladesh. 2012; 8(2): 32-38 14. Amanat M, Togha M, Agah E, Ramezani M, Tavasoli AR, Azizi Malamiri R, et al. Cinnarizine and sodium valproate as the preventive agents of pediatric migraine: A randomized double-blind 
placebo-controlled trial. Cephalalgia. 2020;40(7):665-74

15. Shaygannejad V, Janghorbani M, Ghorbani A, Ashtary F, Zakizade N, Nasr V.'Comparison of the effect of topiramate and sodium valproate in migraine prevention: a randomized blinded crossover study'. Headache. 2006; 46: 642-8

16. Yurekli VA, Akhan G, Kutluhan S, Uzar E, Koyuncuoglu HR, Gultekin F. The effect of sodium valproate on chronic daily headache and its subgroups. The journal of headache and pain. 2008;9(1):37-41

17. Evers S. Treatment of migraine with prophylactic drugs. Expert opinion on pharmacotherapy. 2008;9(15):2565-73

18. Fernández-de-las-Peñas $\mathrm{C}$, Schoenen J. Chronic tension-type headache: what is new?. Current opinion in neurology.
2009;22(3):254-61

19. Couch JR. Amitriptyline Versus Placebo Study Group. Amitriptyline in the prophylactic treatment of migraine and chronic daily headache. Headache: The Journal of Head and Face Pain. 2011;51(1):33-51

20. Snow V, Weiss K, Wall EM, Mottur-Pilson C. 'American Academy of Family Physicians; American College of Physicians-American Society of Internal Medicine. Phar $\neg$ macologic management of acute attacks of migraine and prevention of migraine headache'. Ann Intern Med. 2002;137: 840-9

21. Silberstein SD. Preventive Migraine Treatment. Neurol Clin 2009; 27:429-443. 